\title{
Sanjay Kumur Sharma and Ackmez Mudhoo (Eds): Green Chemistry for Environmental Sustainability
}

\author{
Ken Jones
}

Published online: 20 March 2011

(C) Springer-Verlag 2011

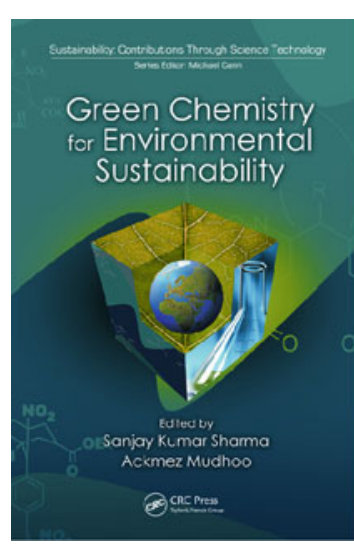

\author{
Bibliography \\ Green Chemistry for Environmental \\ Sustainability \\ Sanjay Kumur Sharma and \\ Ackmez Mudhoo (Eds) \\ CRC Press, Boca Raton, FL, \\ USA, 2010, pp 450 \\ ISBN 978-1-4398-2473-3 \\ GBP 99.00, USD 159.95
}

It cannot be denied that non-renewable and renewable resources alike are over-consumed and that global-predicted population will greatly compound this potentially major problem. From this scenario, the editors claim that, due to ever increasing political pressure created by the climate change theory, the concept of sustainability is rapidly moving into center stage. From this basis, it is then proposed that this is of sufficient importance to create a series entitles "Sustainability: Contributions through Science and Technology". The series is to focus on the role science can play in developing technologies that lessen environmental impacts.

This volume (the first) is constructed around the " 12 Principles of Green Chemistry" (termed as environmentally benign chemistry) devised by Anastas and Warner in 1998. Green chemistry effectively has the target of reducing or eliminating the uses or generation of hazardous substances in the design, manufacture, and application of

K. Jones $(\bowtie)$

Knutsford, Cheshire, UK chemical products. That this definition is as wide as chemistry itself will escape no one, and when the additional requirement of energy demand is brought into the discussion the problem with this proposed series becomes obvious; how is such widely differing subject matter going to be brought into a readable form?

There is no continuity between the 17 chapters in this book and it becomes a matter of selecting an individual chapter (subject) that attracts, to be read in isolation before switching to another topic. Consequently, if only one or two chapters attract then the remainder have no relevance.

There is, however, one over-arching chapter, a condensation of the policies created so far by politicians. Starting with emissions policy in California about 40 years ago, until about two decades ago the US generally led environmental policymaking. This role has now been taken over by the EU with a vengeance. Many would argue that this is the cause of the ever-increasing demise of chemical manufacturing in Europe, with a concomitant switch to more accommodating countries. The final nail for many heavy industries (e.g., glass and cement manufacture), at least in the UK, will be the application of Renewable Obligation Certificates (ROCS), where levies on each tonne of emitted $\mathrm{CO}_{2}$ will have to be paid as a tax to government. As always, and in every environmental book appraised by this reviewer, there is never any form of acknowledgment of the cost of applying the technology, neither the potential loss of employment in the country under surveillance, nor the overall cost to the economy of the countries involved, nor the automatic switch of this local wealth to those countries happy to ignore the global climate change concept.

Perhaps the proposed "sustainability" series will be able to collate the very disparate subject matter into a more coherent pattern; on its own this book does not make an attractive read. 